Research Article

\title{
Thermal Analysis of Square and Circular Perforated Fin Arrays by Forced Convection
}

\author{
Kavita H. Dhanawade ${ }^{\dot{A}^{*}}$, Vivek K. Sunnapwar ${ }^{\dot{A}}$ and Hanamant S. Dhanawade ${ }^{\dot{B}}$ \\ ${ }^{\dot{A}}$ Lokmanya Tilak College of Engineering, Dept. of Mechanical Engineering, Navi Mumbai, India \\ ${ }^{\mathrm{B}} \mathrm{Smt}$. Indira Gandhi College of Engineering Dept. of Mechanical Engineering, Navi Mumbai, India \\ Accepted 07 January 2014, Available online 01 February 2014, Special Issue-2, (February 2014)
}

\begin{abstract}
Heat dissipation is a drastic issue to tackle due to continued integration, miniaturization, compacting and lightening of equipment. Heat dissipaters are not only chosen for their thermal performance; but also for other design parameters that includes weight, cost and reliability, depending on application. The present paper reports an experimental study to investigate the heat transfer enhancement over horizontal flat surface with rectangular fin arrays with lateral square and circular perforation by forced convection. The cross sectional area of the rectangular duct was $200 \mathrm{~mm} \times 80 \mathrm{~mm}$. The data used in performance analysis were obtained experimentally for fin arrays of material aluminum, by varying geometry and size of perforation as well as by varying Reynolds number from $21 \times 10^{4}$ to $8.7 \times 10^{4}$. It is observed that the Reynolds number and size perforation have a larger impact on Nusselt number for the both type of perforations.
\end{abstract}

Keywords: Heat transfer enhancement, fin arrays, perforated fins, forced convection. .

\section{Introduction}

The enhancement of heat transfer is an important subject of thermal engineering. The removal of excessive heat from system components is essential to avoid the damaging effects of burning or overheating. The heat transfer from surface may, in general, be enhanced by increasing the heat transfer coefficient between a surface and its surrounding, or by increasing heat transfer area of the surface, or by both. Extended surfaces that are well known as fins are commonly used to enhance heat transfer in many industries. Various types of fins like rectangular plate fins, square pin-fins and circular pin-fins are commonly used for both natural and forced convection heat transfers. (Ugur and Kadir, 2006) conducted an experiment to investigate the heat transfer and friction loss characteristics in a horizontal rectangular channel having attachments of hollow rectangular profile fins. They studied in-line and staggered fin arrangements for onefixed spanwise and four different streamwise distances. They also found correlation equations for Nusselt number and friction factor. (Souidi and Bontemps, 2001) studied countercurrent gas-liquid flow in narrow rectangular channels simulated by plain and perforated fins. They observed different flow patterns depending on fluid flow rates. (AIEssa, et al, 2004,2008,2009,20012) studied the heat dissipation from a horizontal rectangular fin embedded with square perforation, rectangular perforations with aspect ratio of two, equilateral triangular perforations of bases parallel and towards its fin tip, by

*Corresponding author: Kavita H. Dhanawade

DOI: http://dx.doi.org/10.14741/ijcet/spl.2.2014.20 using finite element technique under natural convection. They compared the results of the perforated fin with its external dimensionally equivalent solid fins. They showed that perforation in the fins enhances heat dissipation rates. Also, the heat transfer of perforated fin enhances with increase in the fin thickness. Suryawanshi and Sane (2009) investigated experimentally the heat dissipation from fin array with inverted notch at the central bottom portion of fin to modify its geometry for enhancement of heat transfer on normal and inverted notched fin arrays (INFAs). They found that the average heat transfer coefficient for INFAs is nearly 30-40\% higher as compared to normal array. (Sara, et al,2000,2001) investigated the thermal performance of solid and perforated rectangular blocks attached on a flat surface in a rectangular duct. When the blocks were perforated, loss in the net energy was recovered and depending on the geometrical and flow conditions, a net gain in energy, up to $20 \%$ was achieved. They also found that a perforation in the blocks enhances the heat transfer and enhancement increases with the increasing degree of perforations.

(Bayram, et al, 2008) experimentally investigated the overall heat transfer, friction factor and the effect of the various design parameters on the heat transfer and friction factor for the heat exchanger equipped with square crosssectional perforated pin fins and circular cross section perforated pin fins in a rectangular channel. They found that the Nusselt number that is based on the projected area would reflect of the variation in the surface area as well as that of the disturbance in the flow due to pin fins on the heat transfer. (Rahman, et al, 2005) have studied numerically as well as experimentally heat transfer

109 | International Conference on Advances in Mechanical Sciences 2014 
characteristics from a horizontal flat plate. They found changes in the average Nusselt number and heat transfer rates due to the use of number of equally spaced high conductivity drilled fins placed at the heater surface at different humid conditions. Thermal performances of the solid fins and drilled fins compared under same condition. They suggested that permeable or drilled fins can be very useful in situations which require higher heat transfer rates than what can be achieved by the use of regular solid fins.(Khoshnevis,et al,2009) carried experiments and investigation showed that increasing perforation's open area ratio augments heat transfer and decreases pressure drop. Increasing perforation angle diameter improves both heat transfer and pressure drop over the channel. (Shaeri, et al, 2009) worked numerically on three-dimensional array of rectangular perforated fins with square window that was arranged in lateral surface and longitudinal of fins. Navier- strokes equations and RNG based k- $\varepsilon$ turbulent model were used. Fin efficiency of perforated fins was determined and compared with the equivalent solid fin. They showed that new perforated fins have higher total heat transfer and considerable weight reduction in comparison with solid fins. (AI-Widyan and AI-Shaarawi 2012) worked numerically on perforated fins under natural convection. They found that the heat transfer from the perforated fins increased with Grashof number as well as by decreasing spacing between the holes.

(Foo and Seng ,2012) investigated experimentally the use of staggered perforated pin fins to enhance the rate of heat transfer while subject to an vertical impinging flow. Chamoli, et al, (2011) worked on CFD to investigate the heat transfer and friction loss characteristics in a horizontal rectangular channel having attachments of circular profile fins over one of its heated surfaces. (Baruah, et al, 2011) worked on CFD to investigate heat transfer and pressure drop characteristics of elliptical pin fins in rectangular channel in a staggered manner. They found that perforated elliptical pinfins perform better than the solid elliptical pin fin. (Wadhah, 2011) experimentally investigated enhancement of natural convection heat transfer from the rectangular fins by circular perforations. He showed that the heat transfer rate and the coefficient of heat transfer increases with increased number of perforation. From the literature survey it has been observed that most of the parameters affecting the heat transfer and pressure drop processes were studied, but none emphasized the experimental investigation of lateral perforated fins with higher Reynolds number, because it requires vast number of experimentation, which enormously increases the experimental cost and period. One more limitation for the study is lack of experimentation in the forced convection.

For many practical applications it is necessary to determine the economical benefits for the heat transfer enhancement.

\section{Nomenclature}

$\mathrm{A}_{\mathrm{T}}$ :Total heat transfer area $\left(\mathrm{m}^{2}\right)$
$\mathrm{C} / \mathrm{H} \quad$ :Clearance ratio
$\mathrm{S} / \mathrm{H} \quad$ :Inter-fin spacing ratio

$\mathrm{D}_{\mathrm{h}}:$ :Hydraulic diameter of the duct (m)

$\mathrm{dt}_{\mathrm{b}} \quad$ :Temperature difference across insulating bricks

$\mathrm{dx}_{\mathrm{b}} \quad$ :Thickness of insulation bricks (m)

$\mathrm{H}$ :Fin height (m)

$\mathrm{t}$ :Thickness of fin (m)

$\mathrm{L} \quad$ :Length of fin $(\mathrm{m})$

$\mathrm{h}_{\mathrm{av}} \quad$ :Average Heat transfer coefficient $\left(\mathrm{W} / \mathrm{m}^{2} \mathrm{~K}\right)$

$\mathrm{K}_{\mathrm{b}} \quad$ :Thermal conductivity of insulating bricks $(\mathrm{W} / \mathrm{m} \mathrm{K})$

$\mathrm{K}_{\mathrm{a}}$ :Thermal conductivity of air $(\mathrm{W} / \mathrm{m} \mathrm{K})$

$\mathrm{Nu}$ :Nusselt number

$\mathrm{Q}_{\mathrm{N}}:$ Net heat transfer rate $(\mathrm{W})$

$\mathrm{Re}:$ :Reynolds number

$\mathrm{N}_{\mathrm{P}} \quad$ :Number of perforations

Q : :Heat input ( Watt)

$\mathrm{T}_{\mathrm{in}}$ :Temperature of inlet air $\left({ }^{\circ} \mathrm{C}\right)$

$\mathrm{T}_{\text {out }} \quad$ :Temperature of outlet air $\left({ }^{\circ} \mathrm{C}\right)$

$\mathrm{T}_{\text {mean }} \quad$ : Mean bulk temperature $\left({ }^{\circ} \mathrm{C}\right)$

$\mathrm{T}_{\mathrm{s}} \quad$ :Average surface temperature of fins $\left({ }^{\circ} \mathrm{C}\right)$

$\mathrm{V}$ :Velocity over test section $(\mathrm{m} / \mathrm{s})$

\section{Greek Symbols}

\section{$\mu \quad$ :Viscosity of $\operatorname{air}(\mathrm{kg} / \mathrm{ms})$ \\ $\rho_{a} \quad$ :Density of $\operatorname{air}\left(\mathrm{kg} / \mathrm{m}^{3}\right)$}

\section{Experimental set up}

The experimental set up is as shown in Fig.1. The internal cross-section of the test section was $200 \mathrm{~mm}$ x $80 \mathrm{~mm} \mathrm{x}$ $260 \mathrm{~mm}$. and the hydraulic diameter $\mathrm{D}_{\mathrm{h}}=114.28 \mathrm{~mm}$. Total length of the duct was $2800 \mathrm{~mm}$. Its position was horizontal and in suction mode. Fig. 2 shows the schematic of the fin arrays used in experiment. Fig.3 shows that cross sectional view of the test test section Geometries of various types of fin arrays are given in Table 1. The $\mathrm{C} / \mathrm{H}$ (Clearance ratio) and (S/H Inter-fin spacing ratio) values were constant i.e. 0.29 and 0.32 respectively. The Reynolds number range was $2.1 \times 10^{4}$ $8.7 \times 10^{4}$ which is based on hydraulic diameter $\left(D_{h}\right)$ of the channel over the test section and average velocity $(\mathrm{V})$. A 450 watt electric heating coil was used as a heat source and was placed between upper plate and bottom base plate. To minimize heat loss through base, the base plate was placed inside the insulating firebricks of $70 \mathrm{~mm}$ thickness, such a way that only upper surface of base plate exposes to duct environment. The variac transformer was used to control the electric power input of the heating coil to get constant heat flux along the test section. The experiments were conducted at heat inputs of 200watts. Total 14 Copper constantan $\mathrm{k}$ type thermocouples were fixed on the fins and base at different points to measure the temperature at different locations. Two thermocouples were fixed inside the insulating bricks at some depth from base plate to find out heat losses to the surrounding. One thermocouple was fixed to measure outlet temperature of the air and the other thermocouple was used to measure the air temperature at inlet. The digital temperature indicator calibrated to \pm 0.1 degree, having range from $0^{\circ} \mathrm{C}$ to $600^{\circ} \mathrm{C}$ was used to measure the temperatures. The mean inlet velocities of the air flow 
entering to the test section was measured by AM4201A THERMO ANEMOMETER. The pressure drop across the test model was measured using two static pressure tapings mounted at the top of the test section. The pressure taps were connected to differential pressure transmitter that can measure in the range $0-100$ pa. (KIMO CP100). The accuracy of the pressure transmitter is $\pm 1.5 \%$ of reading.

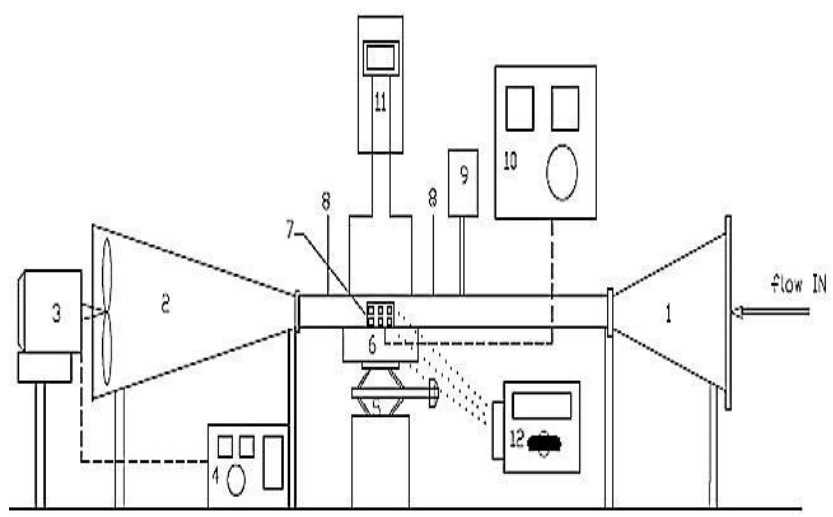

1-Effuser, 2 - Diffuser, 3 - Motor with fan, 4 - Panel Board (1), 5 - Screw jack, 6- Insulation Box, 7 - Fin arrays, 8 - Thermocouples, 9 Anemometer, 10 - Panel Board (2), 11 - Pressure Transmitter , 12 Temperature Indicator.

Fig. 1 Experimental setup

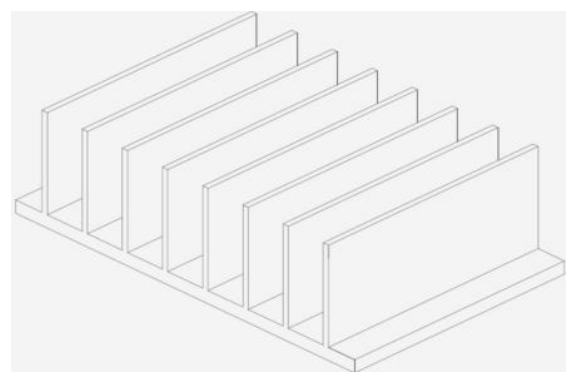

a) Solid fin arrays

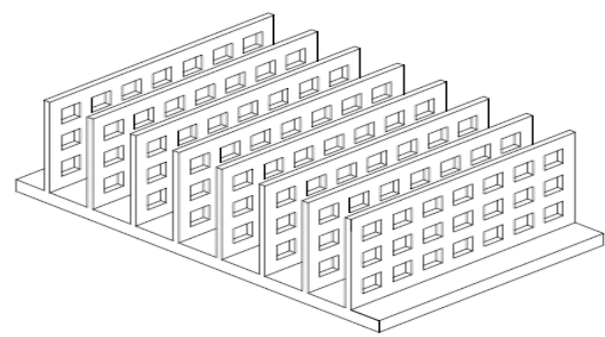

b) Square Perforation fin arrays

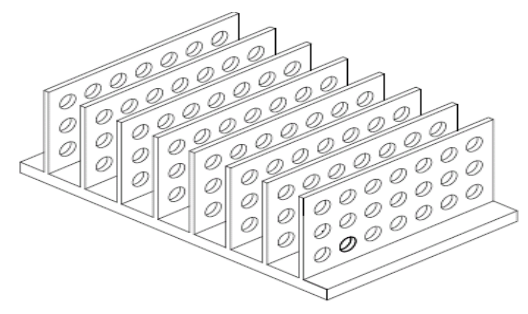

c) Circular perforation fin arrays

Fig. 2 Schematic of the fin arrays

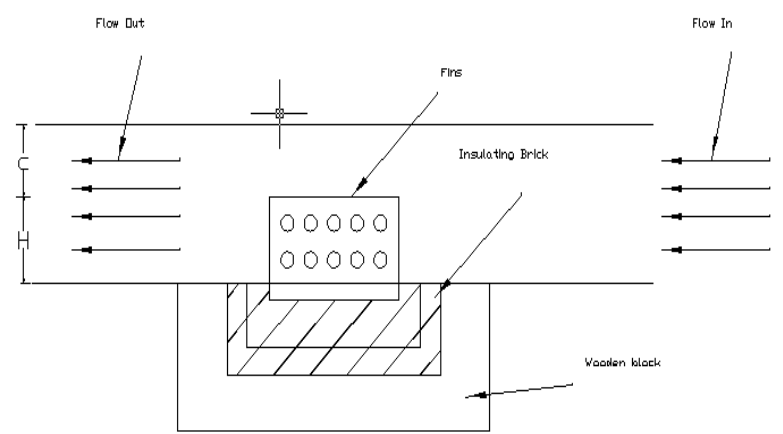

Fig. 3 Cross sectional view of the test section

Table 1Geometry of various types of fin arrays studied

\begin{tabular}{|l|l|l|l|r|}
\hline Type of fins & $\begin{array}{l}\text { Size of fin in } \\
\mathrm{mm}(\mathrm{L} \times \mathrm{H} \times \\
\mathrm{t})(\mathrm{mm})\end{array}$ & $\begin{array}{l}\text { No.of } \\
\text { fins }\end{array}$ & $\begin{array}{l}\text { Size of } \\
\text { perforati } \\
\text { on }(\mathrm{mm})\end{array}$ & $\begin{array}{r}\text { No.of } \\
\text { perfor } \\
\text { ations }\end{array}$ \\
\hline $\begin{array}{l}\text { Without } \\
\text { perforation }\end{array}$ & $120 \times 62 \times 3$ & 8 & - & - \\
\hline \multirow{3}{*}{$\begin{array}{l}\text { With square } \\
\text { perforation }\end{array}$} & $120 \times 62 \times 3$ & 8 & 10 Square & 21 \\
\cline { 2 - 5 } & $120 \times 62 \times 3$ & 8 & 8 Square & 21 \\
\cline { 2 - 5 } & $120 \times 62 \times 3$ & 8 & 6 Square & 21 \\
\hline \multirow{2}{*}{$\begin{array}{l}\text { With } \\
\text { circular } \\
\text { perforation }\end{array}$} & $120 \times 62 \times 3$ & 8 & 10 Dia. & 21 \\
\cline { 2 - 5 } & $120 \times 62 \times 3$ & 8 & 8 Dia. & 21 \\
\cline { 2 - 5 } & $120 \times 62 \times 3$ & 8 & 6 Dia & 21 \\
\hline
\end{tabular}

\section{Data reduction}

The convective heat transfer rate from electrically heated test surface is calculated by using a relation.

$Q_{N}=\mathrm{Q}_{\text {(electrical) }}-\mathrm{Q}_{\text {(conduction) }}-\mathrm{Q}_{\text {(radiation) }}$

The electrical heat input is calculated from the electrical potential and current supplied to the surface. The radiation heat loss can be neglected. Conduction heat loss can be calculated by using (2).

$Q_{\text {(conduction) }}=-K_{b} A_{b} \frac{d t_{b}}{d x_{b}}$

The heat transfer from the test section by convection can be expressed as

$$
Q_{N}=h_{a v} A_{T}\left[T_{s}-\left(\frac{T_{o u t}+T_{i t}}{2}\right)\right]
$$

The area $A_{T}$ in equation (3) is total area of fin that touches fluid passing through the duct. This area includes outer surfaces of fins and also the inner surfaces of perforations. Hence average convective heat transfer coefficient $h_{a v}$ can be find out as

$$
h_{a v}=\frac{Q_{N}}{A_{T}\left(T_{S}-\frac{T_{o u t}+T_{i n}}{2}\right)}
$$

The dimensionless groups are calculated as follows

$N u=\frac{h_{a v} D_{h}}{K_{a}}$ 


$$
\begin{aligned}
R e & =\frac{\rho_{a} V D_{h}}{\mu} \\
f & =\frac{\Delta p}{\left(\frac{L}{D_{h}}\right) \rho \frac{V^{2}}{2}}
\end{aligned}
$$

In all calculations, the values of thermo Physical properties of air are obtained at the bulk mean temperature, which is

$T_{\text {mean }}=\frac{T_{\text {out }}+T_{\text {in }}}{2}$

\section{Results and discussions}

\subsection{Experiment on smooth duct}

In order to have a basis for the evaluation of the effects of the fins, some experiments were carried out for smooth duct (without any fins). Experimental data obtained from these test, the average Nusselt number $\left(N u_{\mathrm{sd}}\right)$ and friction factor $\left(f_{\text {sd }}\right)$ for smooth duct is correlated as the function of Reynolds numberwhich is given below.

$N u_{s d}=0.015 \mathrm{Re}^{0.816}$

$f_{\text {sd }}=0.001 \mathrm{Re}^{0.344}$

Above equations are valid for tested range of Reynolds number from $2.1 \times 10^{4} \leq \mathrm{Re} \leq 8.7 \times 10^{4}$, 200 watt heat input and $\operatorname{Pr} \cong 0.7$.

Experimental results for smooth duct are compared with the correlation of the (Dittus- Bolter, Sieder and Tate, 1997) for turbulent flow in cylindrical ducts, (B. Sahin, A Denmir 2008) and (K Bilen 2006) for rectangular channel and found in good agreement with range of experiment.

\subsection{Heat transfer}

The data used in the analysis is obtained experimentally for varying Reynolds number and geometry of perforation. The Nusselt number $(\mathrm{Nu})$ that is based on the average heat transfer area as well as that the turbulence of flow in the duct. Performance of Nusselt number by varying Reynolds number is shown in Fig. 4 for $6 \mathrm{~mm}$ size of circular and square perforation including solid fin arrays.. Similarly Fig. 5and Fig.6 shows for $8 \mathrm{~mm}$ and $10 \mathrm{~mm}$ size of perforation. The Nusselt numbers of perforated fin arrays as well as solid fin arrays increases with increase in Reynolds number. The Nusselt number of all types of perforated fin arrays is higher than external dimensionally equivalent solid fin arrays for the whole tested range of Reynolds number. It is may be due to perforation and turbulence of flow in the duct. Thermal performance of arrays of square perforation minutely higher than circular perforation of same size for lower range $(15000<\mathrm{Re}<$ 4500) of Reynolds number at the same time the arrays of circular perforation giving slightly better performance for higher range of Reynolds number $(60000<\mathrm{Re}<90000)$.

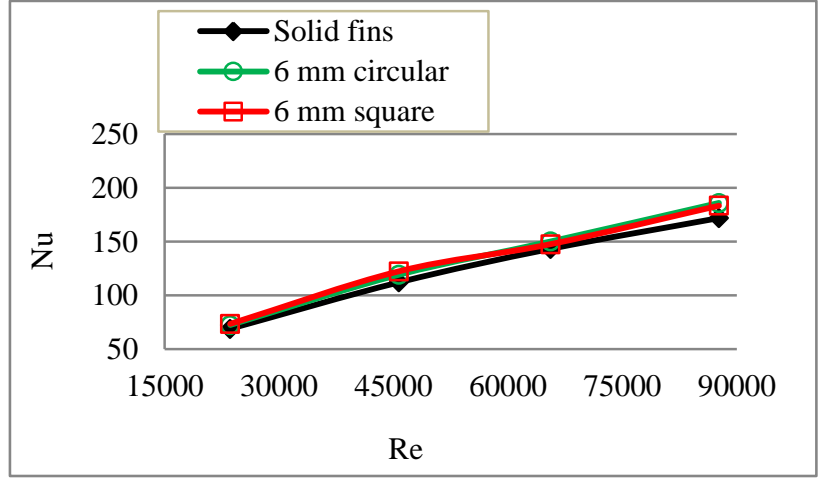

Fig 4 Performance of $\mathrm{Nu} \mathrm{Vs} \mathrm{Re} \mathrm{for} \mathrm{arrays} \mathrm{of} 6 \mathrm{~mm}$ size of circular and square perforation heat input 200 watt

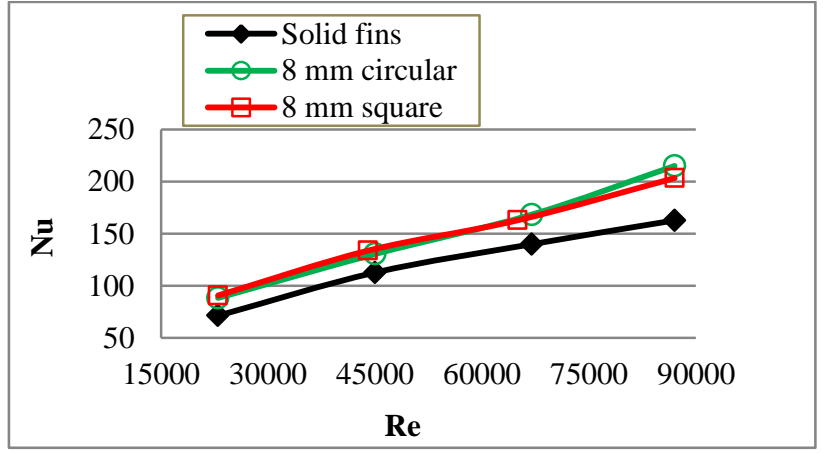

Fig 5 Performance of $\mathrm{Nu}$ Vs Re for arrays of $8 \mathrm{~mm}$ size of circular and square perforation, heat input 200 watt

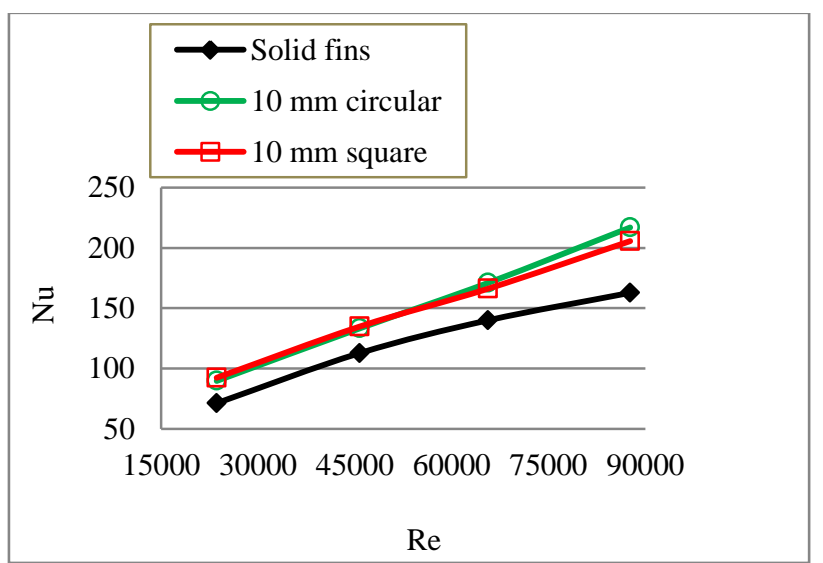

Fig 6 Performance of $\mathrm{Nu}$ Vs Re for arrays of $10 \mathrm{~mm}$ size of circular and square perforation, heat input 200 watt

\subsection{Fin Performance}

For evaluating the effectivness of new lateral perforation fin arrays, it is required to find out fin performance for different size of perforation. To determine effectiveness of fin, the ratio of the actual heat transfer rate from the fin arrays $\left(Q_{f}\right)$ having convection heat transfer coefficient and average surface temperature to heat transfer rate that without fin arrays $\left(Q_{f s}\right)$ at base temperature.

$\varepsilon_{f}=\frac{Q_{f}}{Q_{f_{s}}}$ 
The variation of effectiveness of fin arrays with Reynolds number for different size and shape of perforation are plotted in Fig.7, It shows that the Reynolds number increases, fin effectiveness of the fin arrays decreases for all tpyes of fin arrays. The effectiveness of fins $\left(\varepsilon_{f}\right)$ are higher than unity for all type fin arrays. This means that the use of fin arrays leads to an advantage on the basis of heat heat transfer enhancement.

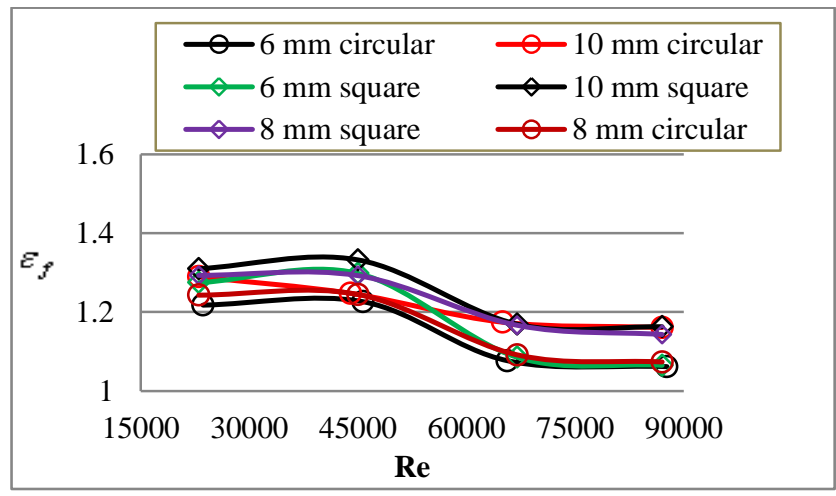

Fig. 7 Performance of fin effectiveness with Reynolds number for different size of perforation, 200 watt

\section{4 percentage improvement of perforated fins}

The comparision of percentage effectiveness of perforated fin arrays to solid fin arrays can calculated using following equation.

Percentag $\left.\notin \varepsilon_{f}\right)=\frac{Q_{p f-} Q_{s f}}{Q_{s f}} \times 100$

$Q_{p f}$ is the heat transfer rate of the perforated fin arrays having convection heat transfer coefficient and average surface temperature .Similarly $Q_{s f}$ is the heat transfer rate of the solid fin arrays Due to perforation, the percentage effectivness $\left(\varepsilon_{f}\right)$ of fin arrays are increases wth increase in size of perforation which is given in the Table no. 2

Table 2 Percentage improvement of perforated fin arrays over solid fin arrays

\begin{tabular}{|l|l|l|}
\hline $\begin{array}{l}\text { Size } \\
\text { perforation }\end{array}$ & $\begin{array}{l}\left(\varepsilon_{f}\right) \text { Percentage } \\
(\%) \text { circular }\end{array}$ & $\begin{array}{l}\left(\varepsilon_{f}\right) \text { Percentage } \\
(\%) \text { square }\end{array}$ \\
\hline $6 \mathrm{~mm}$ & 5.45 & 5.71 \\
\hline $8 \mathrm{~mm}$ & 9.98 & 10.38 \\
\hline $10 \mathrm{~mm}$ & 12.35 & 12.64 \\
\hline
\end{tabular}

\subsection{Friction factor}

The pressure drop over the test section with fin arrays inside the duct were measured under the heated conditions. Friction factor claculated by using equation (9). Fig 8 shows plot of friction factor against the reynolds number for the perforated aswell as solid fin arrays.Friction factor of the arrays of square perforation is highest than all other type of fin arrays.Friction factor of arrays of the perforated fin is more than the arrays of solid fins for tested range of Reynolds number, it may be due to turbalance and resistance againat flow because of perforation.

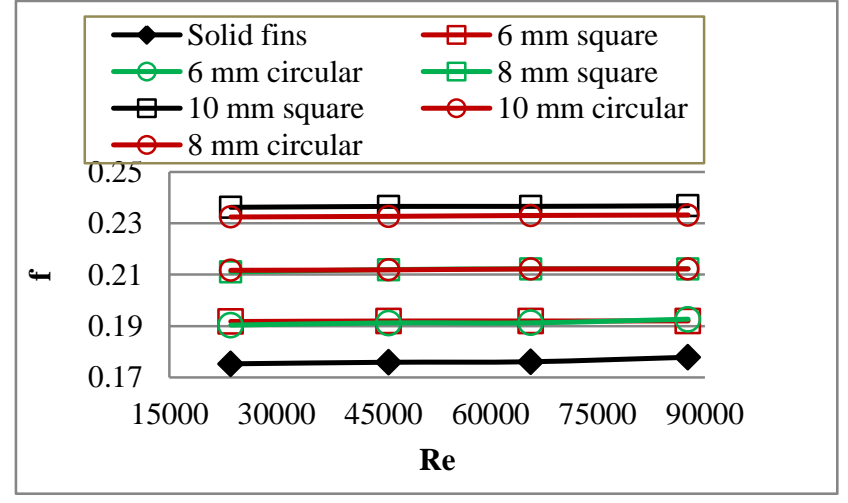

Fig. 8 Plot of friction factor Vs Reynolds number for fin arrays, heat input 200 watt

\section{Experimental uncertainties}

By using the estimation method of ( Moffat R. J. 1988) maximum uncertainties of the investigated non dimensional parameters are $\mathrm{Nu}=4.98 \%, \operatorname{Re}=4.47 \%, f=$ $9.48 \%$. The individual contributions to the uncertainties of the non dimensional parameters for each of the measured physical properties are Velocity of air 3.9\%, Mean temperature $3.7 \%$, Pressure difference $1.13 \%$, Hydraulic diameter $0.1 \%$, Thermal conductivity $0.118 \%$, Dynamic viscosity of air $0.217 \%$, Density of air $0.257 \%$.

\section{Conclusion}

- In this study, the effect of the various parameters like geometry, Reynolds number and friction factor on the heat transfer for the rectangular fins with square and circular perforation are investigated experimentally. The effects of perforation and Reynolds number on the heat transfer characteristics were determined. It is found that the most important parameter affecting the heat transfer is Reynolds number and secondly and geometry of perforation.

- The Nusselt numbers of perforated fin arrays as well as solid fin arrays increases with increase in Reynolds number..

- Percentage improvement in $\mathrm{Nu}$ of Perforated fin arrays over solid fin array is found. Reslut shows that average of percentage improvement of square perforated fin arrays is more than fin arrays of circulated perforated fin of same size.

- Friction factor slightely increases with increase in the size of perforation..

- Utilization of perforated fins increases heat dissipation rate, simultaneously reduction in fins weight, low weight means saving material of fin and which decreases the expenditure on the fin material and related equipment. Hence it may be utilized for cooling of air cooled I C engines and many other industrial applications.

\section{Acknowledgment}

This work was supported by the University of Mumbai 
Reference No. APD /237/412 of 2012. The authors would like to thank the University of Mumbai for funding the research project.

\section{References}

U. Akyol, K. Bilen, (2006) Heat transfer and thermal performance analysis of a surface with hollow rectangular fins, Applied Thermal Engineering, 26 , pp. 209-216.

N. Souidi, A. Bontemps, (2001) Countercurrent gas- liquid flow in plate -fin heat exchangers with plain and perforated fins, International Journal of Heat and Fluid Flow, 22, pp. 450459.

A. H. AIEssa and Fayez M.S. Al-Hussien, (2004) The effect of orientation of square perforations on the heat transfer enhancement from a fin subjected to natural convection, Heat and Mass Transfer, 40, pp. 509-515

A. H. AIEssa and Mohmmed I. Al-Widyan,(2008) Enhancement of natural convection heat transfer from a fin by triangular perforations of bases parallel and toward its tip,Applied Mathematics and Mechanics, 29, pp .1033-1044.

A. H. AIEssa and Mohammed Q. Al-Odat,(2009) Enhancement of natural convection heat transfer from a fin by triangular perforations of bases parallel and toward its base, The Arbian Journal for Science and Engineering, 34 2B, pp. 531-544.

A. H. AIEssa, Ayman M.Maqableh and Shatha Ammourah, (2009) Enhancement of natural convection heat transfer from a fin by rectangular perforations with aspect ratio of two, International journal of Physical Sciences, 4 , pp. 540-547

A. H. M AIEssa,(2012)Augmentation of Fin Natural convection heat dissipation by square perforations, Journal of mechanical engineering and automation 2, pp. 1-5.

S .D. Suryawanshi And N. K. Sane, (2009) Natural convection heat transfer from horizontal rectangular inverted notched fin arrays, Asme, J. Heat Transfer, 131(8),

O. N.Sara, T. Pekdemir, S.Yapici, H.Ersahan, (2000) Thermal performance analysis for solid and perforated blocks attached on a flat surface in duct flow, Energy Conversion and Management, 41, pp.1019-1028.

O. N.Sara, T.Pekdemir, S.Yapici, M.Yilmaz,(2001)Heat transfer enhancement in a channel flow with perforated rectangular blocks, International Journal of Heat and Fluid Flow, 22, pp. 509-518.

B. Sahin, A. Demir, (2008) Thermal performance analysis and optimum design parameters of heat exchanger having perforated pinfins, Energy Conversion and Management, 49, , pp.1684-1695.
B. Sahin, A. Demir ,(2008)Performance analysis of a heat exchanger having perforated square fins, Applied Thermal Engineering, 28, pp. 621-632.

Md. Ashiqur Rahman, Taifur Rahman, Md. Hasibul Mahmud and Md. Mahbubul Alam, (2005) Study of enhanced forced convection heat transfer from a flat plate by solid and drilled fins under different relative humidity condition, Proceedings of the International Conference on Mechanical Engineering, pp. 28-30.

A. Khoshnevis, F. Talati, M. Jalaal, E. Esmalzadeh,(2009)Heat transfer enhancement of slot and hole shape perforations in rectangular ribs of a 3-D channel, 17th Annual International Conference on Mechanical Engineering .

M.R. Shaeri, M.Yaghoubi, (2009) Thermal enhancement from heat sinks by using perforated fins, Energy conversion and Management, 50, pp. 1264-1270.

M.R. Shaeri, M.Yaghoubi, K Jafarpur, (2009) Heat transfer analysis of lateral perforated fin heat sinks, Applied Energy 86, , pp. 2019-2029.

M.R. Shaeri, M.yYaghoubi (2009) Numerical analysis of turbulent convection heat transfer from an array of perforated fins, International Journal of Heat and Fluid Flow, 30 , pp. 218-228

MohamadI.AI-WidyanandAmiadAI-Shaarawi(2012)Numerical investigation of heat transfer enhancement for a perforated fins in natural convection, International Journal of Engineering Research and Applications, 2, pp. 175-184.

Ji Jinn Foo and Chee Seng Tan (2012) Heat transfer enhancement with perforated fin fins subject to impinging flow, International Journal of mechanical computational and manufacturing research, 1, pp. 56-61.

S. Chamoli, R. Chauhan, N.S.Thakur, , (2011) Numerical analysis of heat transfer and thermal performance analysis of surface with circular profile fins, International journal of energy science, 1, pp. 11-18.

M. Baruah, A. Dewan and P. Mahanta, (2011) Performance of elliptical pin fin heat exchanger with three elliptical perforations, CFD letters, 3, pp. 65-73

Wadhah Hussein Abdul Razzaq AI-Doori, (2011) Enhancement of natural convection heat transfer from the rectangular fins by circular perforations, International journal of automotive and mechanical engineering, 4 , , pp. 428-436

Moffat R. J., (1988) Described in uncertanaties in experimental results, experiment therm fluid sci., 1:3-17.

Dittus- Bolter, Sieder and Tate. (1997), Principal of Heat Transfer, by Frank Kreith and Marks.Bohn, 6th edition 